\title{
Diagnostic approaches to malaria in Zambia, 2009-2014
}

\author{
Victor M. Mukonka, ${ }^{1}$ Emmanuel Chanda, ${ }^{2}$ Mulakwa Kamuliwo, ${ }^{2}$ Maha A. Elbadry, ${ }^{3,4}$ \\ Pauline K. Wamulume, ${ }^{2}$ Mercy Mwanza-Ingwe, ${ }^{2}$ Jailos Lubinda, ${ }^{5}$ Lindsey A. Laytner, $, 3,4$ \\ Wenyi Zhang, ${ }^{6}$ Gabriel Mushinge, ${ }^{7}$ Ubydul Haque ${ }^{4,8}$ \\ ${ }^{1}$ Department of Public Health, Copperbelt University, Ndola; ${ }^{2}$ Ministry of Health, National \\ Malaria Control Centre, Lusaka, Zambia; ${ }^{3}$ Department of Environmental and Global \\ Health, University of Florida, Gainesville; ${ }^{4}$ Emerging Pathogens Institute, University of \\ Florida, Gainesville, FL, USA; ${ }^{5}$ Macha Research Trust, Macha, Zambia; ${ }^{6}$ Institute of Disease \\ Control and Prevention, Academy of Military Medical Science, Beijing, China; ${ }^{7}$ Zambian \\ Ministry of Finance, General Statistics Office, Lusaka, Zambia; ${ }^{8}$ Department of Geography, \\ University of Florida, Gainesville, FL, USA
}

\begin{abstract}
Malaria is an important health burden in Zambia with proper diagnosis remaining as one of the biggest challenges. The need for reliable diagnostics is being addressed through the introduction of rapid diagnostic tests (RDTs). However, without sufficient laboratory amenities in many parts of the country, diagnosis often still relies on non-specific, clinical symptoms. In this study, geographical information systems were used to both visualize and analyze the spatial distribution and the risk factors related to the diagnosis of malaria. The monthly reported, district-level number of malaria cases from January 2009 to December 2014 were collected from the National Malaria Control Center (NMCC). Spatial statistics were used to reveal cluster tendencies that were subsequently linked to possible risk factors, using a non-spatial regression model. Significant, spatio-temporal clusters of
\end{abstract}

Correspondence: Victor Mukonka, Department of Public Health, School of Medicine, Copperbelt University, 71191 Ndola, Zambia.

$\mathrm{Tel}+260.212 .618511$.

E-mail: vmukonka@gmail.com

Key words: Clinical malaria; Diagnosis; GIS; Zambia.

Acknowledgements: this work was partly funded by the Emerging Pathogens Institute at the University of Florida and the College of Liberal Arts and Sciences, as part of the University of Florida Pre-eminence Initiative.

Conflict of interest: the authors declare no potential conflict of interest.

Received for publication: 16 February 2015.

Revision received: 4 April 2015.

Accepted for publication: 9 April 2015.

(C) Copyright V. M. Mukonka et al., 2015

Licensee PAGEPress, Italy

Geospatial Health 2015; 10:330

doi:10.4081/gh.2015.330

This article is distributed under the terms of the Creative Commons Attribution Noncommercial License (by-nc 3.0) which permits any noncommercial use, distribution, and reproduction in any medium, provided the original author(s) and source are credited. malaria were spotted while the introduction of RDTs made the number of clinically diagnosed malaria cases decrease by $33 \%$ from 2009 to 2014. The limited access to road network(s) was found to be associated with higher levels of malaria, which can be traced by the expansion of health promotion interventions by the NMCC, indicating enhanced diagnostic capability. The capacity of health facilities has been strengthened with the increased availability of proper diagnostic tools and through retraining of community health workers. To further enhance spatial decision support systems, a multifaceted approach is required to ensure mobilization and availability of human, infrastructural and technological resources. Surveillance based on standardized geospatial or other analytical methods should be used by program managers to design, target, monitor and assess the spatio-temporal dynamics of malaria diagnostic resources country-wide.

\section{Introduction}

Zambia has one of the highest burdens of malaria in the world (WHO, 2013). Resurgence of this disease has been confirmed in many parts of the country with millions of cases reported each year by the Zambian National Malaria Control Center (NMCC) (Kamuliwo et al., 2013). In the last five years, international cooperating partners, together with the Government of Zambia, have invested 8 USD per capita of the inhabitants in the country to control malaria (Haque et al., 2014). With this investment, a large scale-up of interventions for malaria control has been implemented country-wide.

Without parasitological confirmation, the diagnosis of malaria relies on non-specific, clinical symptoms, mainly fever. The Ministry of Health has adopted artemisinin-based combination therapy (ACTs) for patients with malaria infection (NMCC, 2014). A revision of the treatment regimen for both uncomplicated and complicated malaria was released in 2014, adding artemether-lumefantrine (AL) to ACT as first line of treatment (NMCC, 2014) to be given within 24 hours of onset of symptoms. However, the use of rapid diagnostic tests (RDTs) was first initiated as a pilot project in some districts in 2005 to 2006 (Bharti et al., 2008) and was scaled up for country-wide use in 2008 (Keating et al., 2009). In 2009, Zambia began separate reporting for clinical and parasitological diagnosis. By 2012, approximately 50\% of the reported cases were confirmed by either microscopy or by RDT (Kamuliwo et al., 2013). 
According to the Guidelines on the Diagnoses and Treatment of Malaria in Zambia (NMCC, 2014), the Ministry of Health recommends laboratory-confirmed diagnosis of malaria, where capacity exists, prior to administering treatment. The guidelines further recommend that treatment, on the sole basis of clinical suspicion, should only be considered when a parasitological diagnosis is not accessible. The results of parasitological diagnosis should be available within a short time (less than two hours) of the patient presenting at a health facility. In case of delayed, or in the absence of, parasitological diagnosis, patients with suspected severe malaria, and other high-risk groups, should be treated immediately on clinical grounds.

President's Malaria Initiative (PMI) support has resulted in significant progress in training community health workers (CHWs) on the use of RDTs (Mukonka et al., 2014). Positive RDT rates were the highest among febrile cases reporting to CHWs for treatment (Hamainza et al., 2014). Introduction of RDT and ACT consumption led to a large decline in reported malaria cases in parts of Zambia (Masaninga et al., 2012; Eisele et al., 2013). Rapid diagnostic test was used to diagnose malaria for $98.3 \%$ cases in some clinics (Eisele et al., 2013). A higher proportion of laboratory tests confirmed by microscopy (67.4\%), as opposed to clinically diagnosed malaria, was reported in one district in Zambia (Eisele et al., 2013) and it is felt that the use of RDTs in the diagnosis of malaria will affect national (and global) malaria control strategies. Geospatial technologies have created new opportunities for public health administrators to enhance planning, monitoring, analysis and management of health system. The aim of this study was to investigate the progress of malaria diagnosis, spatial distribution of the absolute number of cases diagnosed clinically as well as the determinants and underlying risk factors.

\section{Materials and Methods}

\section{Study area and population}

Zambia, located in the Southern African region with a population of 14.6 million, is endemic for malaria throughout the country. There is moderate-to-high transmission in all districts, which is generally more pronounced from November to April (Kamuliwo et al., 2013). However, there are regional epidemiological variations with the highest annual incidence of malaria in the northeast (Luapula Province), from where there is a decreasing gradient in malaria transmission intensity towards the Southwest. Specifically, Lusaka City and the area around the city stands out as having the lowest incidence. The majority of Zambia's population (60.5\%) live in the rural areas, where access to health-care treatment services remains a challenge. It is currently estimated that in urban areas, approximately $99 \%$ of households are situated within five $\mathrm{km}$ of a health facility, compared to $50 \%$ in the rural areas (PMI, 2014).

Population (demographic) and housing (number of houses in each district) data at the district level were collected from the Central Statistical Office for 2000 and 2010 and were projected for 2009, 2011, 2012, 2013 and 2014 using an exponential population growth model (Kamuliwo et al., 2013).

Zambia has many lakes and rivers and an extensive road network covering most of the country, while its railroad network connects the southern part of the country with the northern part (Figure 1). The spatial data includes the district boundaries as well as the geo-coded locations of Zambia's 1426 health facilities were collected from the Ministry of Environment and Natural Resources department, Zambia. The health facilities are distributed across the country to ensure both an accurate and early malaria diagnosis, at least at the district level.

\section{Malaria data and management}

Monthly reported, district-level, diagnostic data of malaria incidence from January 2009 to December 2014 were collected from the NMCC. These reports show which cases were laboratory confirmed, and which were only based on clinical symptoms. Diagnosis was carried out at the community level by CHWs at health facilities, private clinics or health facilities run by non-government organizations (NGOs) or faith-based organizations. The study looked at all cases of malaria reported in the health facilities categorizing the data into i) clinically diagnosed malaria based on fever and other clinical signs; and ii) confirmed malaria diagnosis, either through microscopy or by RDT using the Malaria Ag P.f/Pan test (Standard Diagnostics, Yongin-si, Republic of Korea), a test for the Plasmodium falciparum histidine-rich protein II antigen and the Plasmodium lactate dehydrogenase constituent (Bharti et al., 2008; Keating et al. 2009; Kamuliwo et al., 2013).

To ensure accurate and early malaria diagnosis at least at the district level, out of the 1426 total health facilities available in the country, only 417 (29\%) have microscopy capacity. The public health facilities are responsible for supplying CHWs in their catchment areas with RDT tests (available at all such centres), which are mainly used by CHWs at the community level and where laboratory diagnosis is not available. All health facilities with microscopy capacity also use RDT due to constraints with respect to human resources for microscopy. CHWs, health centres, hospitals and other health facilities run by NGOs and private organizations, they regularly submit reports (in paper form) to the District Health Office (DHO). The DHOs further submit district-level data to provincial health offices, where they are analysed and results returned to the DHO with a report sent to the NMCC.

\section{Spatial and statistical analysis}

Mean centres (centroids) were created for each district using ArcGIS software version 10.1 (Esri, Redlands, CA, USA). Districts were categorized whether or not they were in close proximity to water bodies (bordering on lakes/rivers), and whether or not they were easily accessible by roads or railroads area. Distances were calculated from the centroid centre to nearest road/rail road station and categorized as follows $(\leq 2$ $\mathrm{km}=\operatorname{good}$ access; $>2 \mathrm{~km}=$ limited access) because sick people are more likely to present at services if within $2 \mathrm{~km}$ (Haque et al. 2010a).

GeoDa software (Anselin et al., 2006) was used to detect spatial autocorrelation. Global spatial autocorrelation, calculated by Moran's $I$ (Moran, 1950), was used to explore the overall clustering of annual malaria cases from 2009 to 2014 in Zambia. This index varies between -1 and +1 , with 0 indicating spatially random distribution, while negative values mean dispersed distributions as opposed to positive values that signify clustered distributions.

Spatial smoothing can be used to reduce random variations associated with small populations and enables identification of spatial clusters of clinical cases that may not be apparent from direct observation of the raw data (Luc, 2005). Using this approach, districts with small populations at risk tend to have their observed rates adjusted more heavily towards the neighbourhood average than for more densely populated districts. The annual, average rate of cases diagnosed clinically from 2009-2014 was spatially smoothed by employing an empirical Bayes spatial smoothing procedure (Zhang et al., 2014) using GeoDa software, version 0.9.5-i (Anselin et al., 2006).

Monthly clinical cases and the aggregated annual population at the district level for 2009-2014 were linked with district shape files. SaTScan version 9.3 (Kulldorff, 2014) was used to detect spatio-temporal clusters of clinical malaria cases. For this analysis, we used retrospective space-time (RST) analysis scanning for clusters with high 
rates using the space-time permutation (SPT) model to ensure adequate power to define the clusters (Haque et al., 2013).

Comparative characteristics of high-risk and low-risk districts with respect to malaria, the population density of each district, communication possibility by road or rail, number of health facilities and water body variables were considered risk factors. Descriptive and negative binomial regression analyses were done to understand seasonality and the risk factors. Statistical analyses were performed with STATA, version 11 (StataCorp LP, College Station, TX, USA).

\section{Results}

Zambia reported 6.13 million malaria cases in 2014 . The proportion of clinically diagnosed malaria cases decreased from $73 \%$ in 2009 to $33 \%$ in 2014 (Figure 2A). Although malaria transmission continued throughout the year, most clinically diagnosed cases were reported from February to April (Figure 2B). Looking at each year individually, the total number of malaria cases (both clinically diagnosed and laboratory confirmed ones) increased from November until end of the year. This trend continued until March of the following year, except in 2012, 2013 and 2014 (Figure 2B).

\section{Spatial clusters}

Each year, spatial clusters of malaria cases were reported, with 31 statistically significant clusters were observed (Table 1). The strongest clusters were reported in 2014 (Figure 3). Only one district in the southern part of Zambia reported less than $1 \%$ of all malaria diagnoses as clinically diagnosed cases, while five districts reported less than $10 \%$. In contrast, clinically diagnosed cases dominated in seven districts (>90\%) (Figure 4). Almost 50\% of districts reported more than $10-50 \%$ clinically diagnosed malaria cases. Districts having limited access to the road network were associated with higher proportion of clinically diagnosed malaria cases (Table 2).

\section{Discussion}

Zambia is making progress towards proper and accurate diagnosis of malaria based on parasitological diagnosis. The number of malaria cases only diagnosed by clinical signs has dropped in Zambia over the last few years. Training and/or re-training of CHWs and the increased use of RDTs have contributed to the reduction of cases with the diagnosis only based on clinical symptoms. However, the country needs to improve malaria diagnosis further and reduce the number of diagnoses based on clinical signs from 49 to $0 \%$ in line with the Zambian national

Table 1. Spatial clusters of clinically diagnosed malaria cases in Zambia 2009-2014.

\begin{tabular}{|c|c|c|c|c|c|c|}
\hline Year & Cluster & Number of cases & Number of expected cases & Observed/expected ratio & Relative risk & $\mathbf{P}$ \\
\hline 2009 & $\begin{array}{l}1 \\
2 \\
3 \\
4\end{array}$ & $\begin{array}{c}78,011 \\
16,993 \\
94,750 \\
109,943\end{array}$ & $\begin{array}{c}25,072 \\
3599 \\
38,660 \\
38,463\end{array}$ & $\begin{array}{l}3.10 \\
4.72 \\
2.45 \\
3.25\end{array}$ & $\begin{array}{l}3.18 \\
4.77 \\
2.53 \\
3.35\end{array}$ & $\begin{array}{l}<0.001 \\
<0.001 \\
<0.001 \\
<0.001\end{array}$ \\
\hline 2010 & $\begin{array}{l}1 \\
2 \\
3 \\
4 \\
5\end{array}$ & $\begin{array}{c}182,491 \\
99,414 \\
148,007 \\
40,097 \\
55,611\end{array}$ & $\begin{array}{c}56,442 \\
20,675 \\
48,684 \\
8544 \\
17,411\end{array}$ & $\begin{array}{l}3.23 \\
4.81 \\
3.04 \\
4.69 \\
3.19 \\
\end{array}$ & $\begin{array}{l}3.39 \\
4.96 \\
3.18 \\
4.77 \\
3.27\end{array}$ & $\begin{array}{l}<0.001 \\
<0.001 \\
<0.001 \\
<0.001 \\
<0.001\end{array}$ \\
\hline 2011 & $\begin{array}{l}1 \\
2 \\
3 \\
4 \\
5\end{array}$ & $\begin{array}{c}176,812 \\
120,042 \\
117,693 \\
46,866 \\
35,554\end{array}$ & $\begin{array}{c}60,607 \\
39,678 \\
35,491 \\
12,553 \\
7852\end{array}$ & $\begin{array}{l}2.92 \\
3.03 \\
3.32 \\
3.73 \\
4.53\end{array}$ & $\begin{array}{l}3.08 \\
3.16 \\
3.49 \\
3.83 \\
4.63\end{array}$ & $\begin{array}{l}<0.001 \\
<0.001 \\
<0.001 \\
<0.001 \\
<0.001\end{array}$ \\
\hline 2012 & $\begin{array}{l}1 \\
2 \\
3 \\
4 \\
5 \\
6\end{array}$ & $\begin{array}{l}122,600 \\
117,515 \\
115,549 \\
75,620 \\
84,115 \\
39,119\end{array}$ & $\begin{array}{l}38,870 \\
37,844 \\
45,428 \\
23,684 \\
30,921 \\
11,260 \\
\end{array}$ & $\begin{array}{l}3.15 \\
3.11 \\
2.54 \\
3.19 \\
2.72 \\
3.47\end{array}$ & $\begin{array}{l}3.29 \\
3.24 \\
2.67 \\
3.31 \\
2.85 \\
3.57\end{array}$ & $\begin{array}{l}<0.001 \\
<0.001 \\
<0.001 \\
<0.001 \\
<0.001 \\
<0.001\end{array}$ \\
\hline 2013 & $\begin{array}{l}1 \\
2 \\
3 \\
4 \\
5 \\
6\end{array}$ & $\begin{array}{c}158,937 \\
82,647 \\
75,826 \\
102,243 \\
71,395 \\
39,380\end{array}$ & $\begin{array}{l}52,757 \\
15,640 \\
26,787 \\
41,924 \\
26,778 \\
11,289\end{array}$ & $\begin{array}{l}3.01 \\
5.28 \\
2.83 \\
2.44 \\
2.67 \\
3.49\end{array}$ & $\begin{array}{l}3.15 \\
5.44 \\
2.90 \\
2.52 \\
2.73 \\
3.55\end{array}$ & $\begin{array}{l}<0.001 \\
<0.001 \\
<0.001 \\
<0.001 \\
<0.001 \\
<0.001\end{array}$ \\
\hline 2014 & $\begin{array}{l}1 \\
2 \\
3 \\
4 \\
5\end{array}$ & $\begin{array}{c}282,619 \\
1,265,891 \\
198,012 \\
129,676 \\
50,520\end{array}$ & $\begin{array}{c}66,792 \\
851,934 \\
57,396 \\
58,244 \\
24,016\end{array}$ & $\begin{array}{l}4.23 \\
1.49 \\
3.45 \\
2.23 \\
2.10\end{array}$ & $\begin{array}{l}4.75 \\
2.74 \\
5.10 \\
3.19 \\
2.59\end{array}$ & $\begin{array}{l}<0.001 \\
<0.001 \\
<0.001 \\
<0.001 \\
<0.001\end{array}$ \\
\hline
\end{tabular}


malaria control policy, which calls for $100 \%$ laboratory diagnosis of all suspected malaria cases. A high number of malaria cases were diagnosed clinically during the months of November and April each year. The NMCC in Zambia needs to thoroughly investigate and ensure that the supply of RDT in all endemic malaria zones does not become interrupted. The management of the supply chain requires strengthening to avoid stock-out at the health facility level. Incorporating geospatial methods will help to supplement the design, targeting, monitoring, assessment of malaria diagnosis and prevalence rates throughout the country. This can enhance monitoring by enabling more accurate and timely resource allocation.

Some health facilities delay ordering and restocking, a situation that leads to sporadic empty shelves even with RDTs being available at the central medical stores. Skills of personnel in charge of ordering RDTs should be enhanced to match the demand of the testing services. The introduction of provincial hubs by the Ministry of Health is also expected to reduce the time spent transporting medical supplies, which include malaria-related commodities like RDTs. Provincial hubs will also need to cut costs, improve the supply chain management and ensure that RDTs are available at all times. The demand for diagnostic services has improved partly due to health promotion and education efforts that emphasize the importance of testing before treatment.

All districts in Zambia, except one, reported more than $10 \%$ clinically diagnosed malaria. This situation requires the urgent attention of all stakeholders, especially policy makers, program implementers and DHOs. One reason for finding significant clusters of such cases could have been due to a shortage, or lack of, timely supply of diagnostic kits. However, this needs further investigation to find out the real problem. All districts, reporting more than $50 \%$ cases clinically diagnosed malaria need urgent attention as they represent a major obstacle to ensuring universal malaria diagnosis and treatment in Zambia. It is not clear why these districts still have more than $90 \%$ clinically diagnosed cases after extended use of RDTs was rolled out in 2005-2006. A study has shown that appropriately trained and supervised CHWs can use RDTs, both safely and accurately, in community practice in Zambia (Counihan et al., 2012).

Table 2. Determinants of clinical malaria cases in Zambia.

$\begin{array}{lc} & \text { Clinical cases PRR (95\% CI) } \\ \text { Year } & 1 \\ 2009 & 1.35(0.90-2.03) \\ 2010 & 1.09(0.73-1.63) \\ 2011 & 1.02(0.68-1.53) \\ 2012 & 1.30(0.85-1.95) \\ 2013 & 0.98(0.65-1.48) \\ 2014 & 1.00(0.99-1.00) \\ \text { Density of population } & 0.99(0.98-1.01) \\ \text { Number of health facilities in each district } & 1 \\ \text { Access to railroad in each district } & \\ \text { No } & 0.95(0.71-1.28) \\ \text { Yes } & 1 \\ \text { Proximity to water body in each district } & \\ \text { No } & 0.91(0.68-1.21) \\ \text { Yes } & 1 \\ \text { Access to formal road in each district } & 1.38(1.07-1.77) \\ \quad \text { Good access } & \\ \text { Limited access } & \end{array}$

PRR, prevalence rate ratio; $\mathrm{Cl}$, confidence interval.
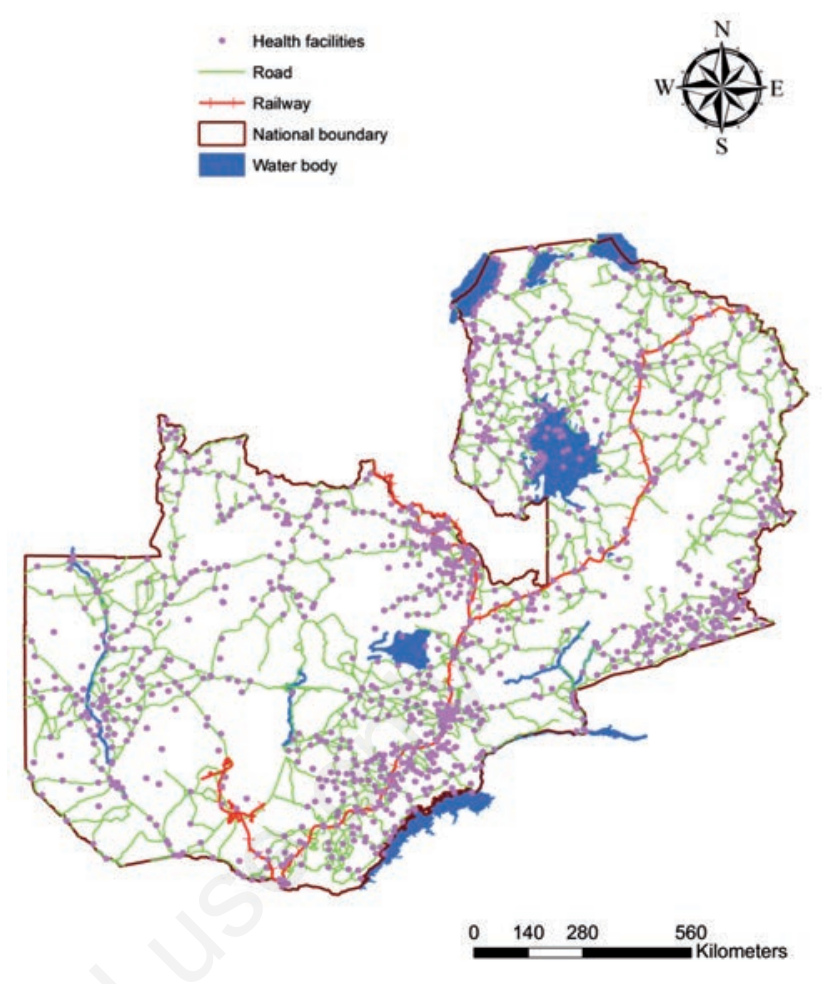

Figure 1. Map of health facilities, roads, railway lines and water bodies in Zambia.
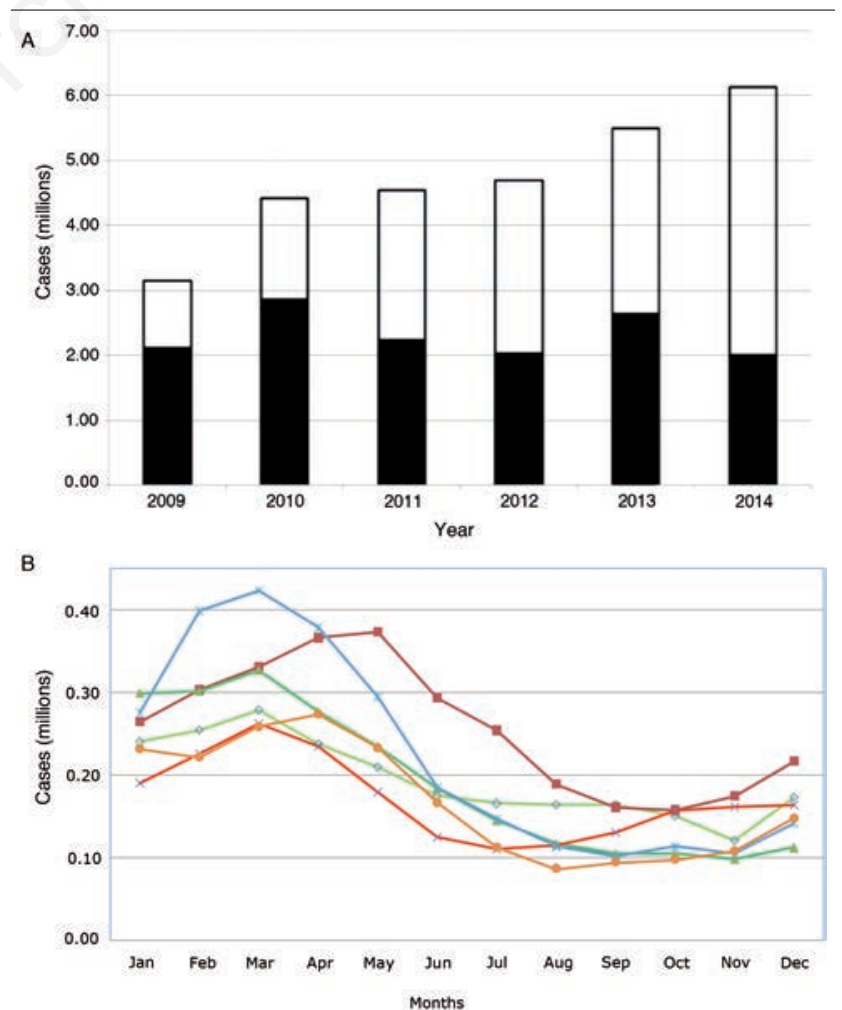

Figure 2. A) Trends in malaria diagnostics in Zambia 2009 to 2014 (black bars indicate clinically diagnosed cases and open bars cases confirmed by microscopy or rapid diagnostic test); B) clinical cases (light green, magenta, deep green, red, blue and dark yellow color represents 2009, 2010, 2011, 2012, 2013 and 2014 respectively). 

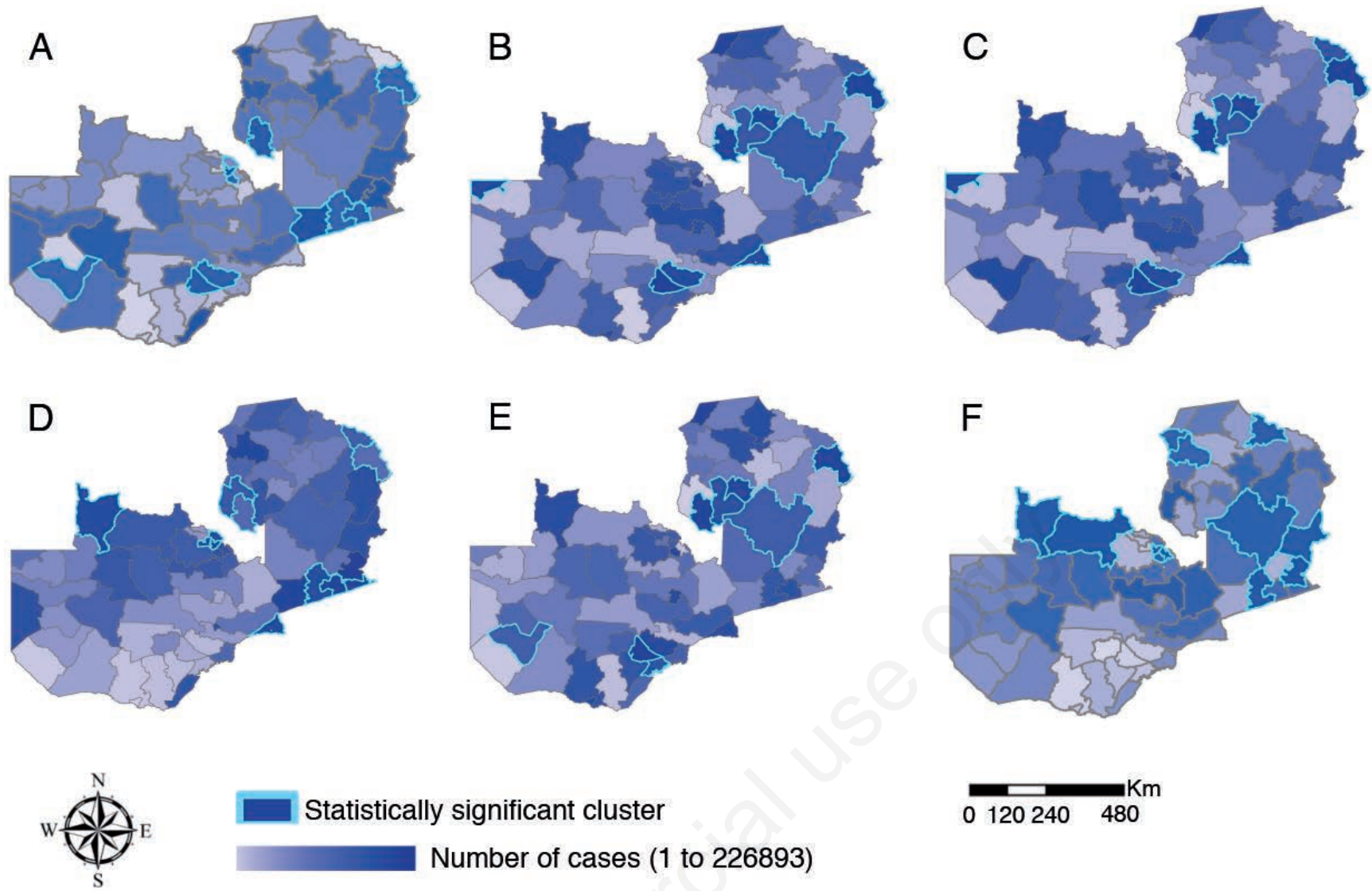

Statistically significant cluster

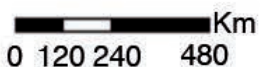

Number of cases (1 to 226893)

Figure 3. Spatial clusters of clinical malaria cases in Zambia from 2009 (A) to 2014 (F).

Further investigation should be carried out targeting health facilities that have been reporting higher numbers of clinically diagnosed malaria cases. This will contribute toward successful malaria control. The capacity of health facilities should be further strengthened through training and retraining of CHWs and expansion of health promotion interventions including: community mobilization and empowerment, such as utilization of electronic media (television and radio including community radio stations) and printed media (newspapers, leaflets, posters) to create awareness. In addition, both timely and accurate diagnosis as well as the benefits of testing before commencement of malaria treatment should be emphasized. Regularly updated malaria risk maps (Haque et al., 2010b; Reid et al., 2010, 2012; Haque et al., 2011; Wang et al., 2014) can help the NMCC to monitor progress and mobilize resources. Distance, population density, treatment seeking behavior and other health facilities should be considered (Ahmed et al., 2009; Haque et al., 2012; Simon et al., 2013).

Accessibility (road network) proved to be a significant risk factor in this study for clinical diagnosis. Distance is an important factor in health seeking behavior (Haque et al., 2010a). It was observed that higher clinical malaria cases were partly associated with remoteness. Few districts have limited access to road (Figure 1). Moreover, the timely supply of diagnostic RDT kits in these districts might also be a key contributor to this situation and may ensure both accurate and early diagnosis. The trend of diagnosis among clinicians should be investigated in the eight districts that reported more than $90 \%$ clinically diagnosed cases. This study has several limitations. Limited number of $(\sim 2-5 \%)$ health facilities may not be active or may not have submitted reports. It should be noted that, at the time of analysis, the data (number of health facilities and road network) used was for 2010, and the situation may have changed after this time.

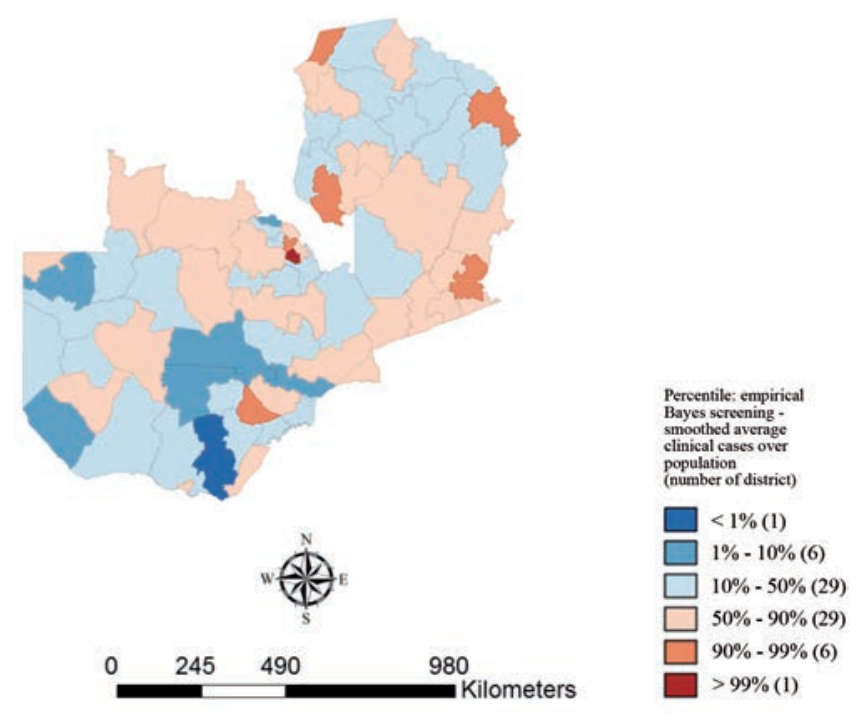

Figure 4. Spatial smoothed percentile map of clinical malaria in Zambia 2009-2014 based on empirical Bayesian analysis. 


\section{Conclusions}

Zambia has succeeded in reducing the number of clinically diagnosed as opposed to laboratory confirmed malaria. This study identified that limited access to a road network was associated with higher reporting of clinical malaria cases. The underlying reason for this observation should be investigated in relation to identified spatio-temporal clusters, with special reference to the specific months where significant numbers of malaria were reported. The NMCC in Zambia should ensure, supply and distribute diagnostic kits in advance, before the peak malaria transmission period to all remote areas of the country. In the case of malaria diagnosis, the country should promote behavior change communication using both social and electronic media. By incorporating other readily available geospatial or other analytical methods that will allow spatial decision support systems, both resources and stock monitoring will be strengthened. This can enhance surveillance by enabling accurate and timely resource allocation.

\section{References}

Ahmed SM, Haque R, Haque U, Hossain A, 2009. Knowledge on the transmission, prevention and treatment of malaria among two endemic populations of Bangladesh and their health-seeking behavior. Malaria J 8:173.

Anselin L, Syabri I, Kho Y, 2006. GeoDa: an introduction to spatial data analysis. Geogr Anal 38:5-22.

Bharti PK, Silawat N, Singh PP, Singh MP, Shukla M, Chand G, Dash AP, Singh N, 2008. The usefulness of a new rapid diagnostic test, the First Response Malaria Combo (pLDH/HRP2) card test, for malaria diagnosis in the forested belt of central India. Malaria J 7:126.

Counihan H, Harvey SA, Sekeseke-Chinyama M, Hamainza B, Banda R, Malambo T, Masaninga F, Bell D, 2012. Community health workers use malaria rapid diagnostic tests (RDTs) safely and accurately: results of a longitudinal study in Zambia. Am J Trop Med Hyg 87:5763.

Eisele TP, Silumbe K, Yukich J, Hamainza B, Keating J, Bennett A, Miller $\mathrm{JM}, 2013$. Measuring coverage in MNCH: accuracy of measuring diagnosis and treatment of childhood malaria from household surveys in Zambia. PLoS Med 10:e1001417.

Hamainza B, Moonga H, Sikaala CH, Kamuliwo M, Bennett A, Eisele TP, Miller J, Seyoum A, Killeen GF, 2014. Monitoring, characterization and control of chronic, symptomatic malaria infections in rural Zambia through monthly household visits by paid community health workers. Malaria J 13:128.

Haque U, Glass GE, Bomblies A, Hashizume M, Mitra D, Noman N, Haque W, Kabir M, Yamamoto T, Overgaard HJ, 2013. Risk factors associated with clinical malaria episodes in Bangladesh: a longitudinal study. Am J Trop Med Hyg 88:727-32.

Haque U, Hashizume M, Sunahara T, Hossain S, Ahmed SM, Haque R, Yamamoto T, Glass GE, 2010a. Progress and challenges to control malaria in a remote area of Chittagong hill tracts, Bangladesh. Malaria J 9:156.

Haque U, Magalhaes RJS, Reid HL, Clements ACA, Ahmed SM, Islam A, Yamamoto T, Haque R, Glass GE, 2010b. Spatial prediction of malaria prevalence in an endemic area of Bangladesh. Malaria J 9:120.

Haque U, Overgaard HJ, Clements AC, Norris DE, Islam N, Karim J, Roy S, Haque W, Kabir M, Smith DL, Glass GE, 2014. Malaria burden and control in Bangladesh and prospects for elimination: an epidemiolog- ical and economic assessment. Lancet Glob Health 2:e98-e105.

Haque U, Scott LM, Hashizume M, Fisher E, Haque R, Yamamoto T, Glass $\mathrm{GE}, 2012$. Modelling malaria treatment practices in Bangladesh using spatial statistics. Malaria J 11:63.

Haque U, Sunahara T, Hashizume M, Shields T, Yamamoto T, Haque R, Glass GE, 2011. Malaria prevalence, risk factors and spatial distribution in a hilly forest area of Bangladesh. PLoS One 6:e18908.

Kamuliwo M, Chanda E, Haque U, Mwanza-Ingwe M, Sikaala C, KatebeSakala C, Mukonka VM, Norris DE, Smith DL, Glass GE, Moss WJ, 2013. The changing burden of malaria and association with vector control interventions in Zambia using district-level surveillance data, 2006-2011. Malaria J 12:437.

Keating J, Miller JM, Bennett A, Moonga HB, Eisele TP, 2009. Plasmodium falciparum parasite infection prevalence from a household survey in Zambia using microscopy and a rapid diagnostic test: implications for monitoring and evaluation. Acta Trop 112:277-82.

Kulldorff M, 2014. SaTScan TM user guide for version 9.3. Available from: www.satscan.org/techdoc.html

Luc A, 2005. Exploring spatial data with GeoDa: a workbook. Available from: https:/geodacenter.asu.edu/og_tutorials

Masaninga F, Sekeseke-Chinyama M, Malambo T, Moonga H, Babaniyi 0, Counihan H, Bell D, 2012. Finding parasites and finding challenges: improved diagnostic access and trends in reported malaria and antimalarial drug use in Livingstone district, Zambia. Malaria J 11:341.

Moran PA, 1950. Notes on continuous stochastic phenomena. Biometrika $37: 17-23$

Mukonka VM, Chanda E, Haque U, Kamuliwo M, Mushinge G, Chileshe J, Chibwe KA, Norris DE, Mulenga M, Chaponda M, Muleba M, Glass GE, Moss WJ, 2014. High burden of malaria following scale-up of control interventions in Nchelenge District, Luapula Province, Zambia. Malaria J 13:153.

NMCC, 2014. Guidelines for the diagnosis and treatment of malaria in Zambia. Available from: http//www.nmcc.org.zm/files/Guidelineson DiagnosisandTreatmentofMalariainZambia_4thEd_2-24-14.pdf

PMI, 2014. President's malaria initiative. Zambia Malaria Operational Plan FY 2014. Available from: http://www.pmi.gov/docs/defaultsource/default-document-library/malaria-operational-plans/fyl4/zambia_mop_fy14.pdf?sfvrsn=8

Reid H, Haque U, Clements ACA, Tatem AJ, Vallely A, Ahmed SM, Islam A, Haque R, 2010. Mapping malaria risk in Bangladesh using bayesian geostatistical models. Am J Trop Med Hyg 83:861-7.

Reid HL, Haque U, Roy S, Islam N, Clements AC, 2012. Characterizing the spatial and temporal variation of malaria incidence in Bangladesh, 2007. Malaria J 11:170.

Simon C, Moakofhi K, Mosweunyane T, Jibril HB, Nkomo B, Motlaleng M, Ntebela DS, Chanda E, Haque U, 2013. Malaria control in Botswana, 2008-2012: the path towards elimination. Malaria $\mathrm{J}$ 12:458.

Wang L, Hu W, Soares Magalhaes RJ, Bi P, Ding F, Sun H, Li S, Yin W, Wei L, Liu Q, Haque U, Sun Y, Huang L, Tong S, Clements AC, Zhang W, Li C, 2014. The role of environmental factors in the spatial distribution of Japanese encephalitis in mainland China. Environ Int 73:1-9.

WHO, 2013. World malaria report. World Health Organization, Geneva, Switzerland. Available from: http://www.who.int/malaria/publications/world_malaria_report_2013/en/index.html

Zhang WY, Wang LY, Liu YX, Yin WW, Hu WB, Magalhaes RJ, Ding F, Sun HL, Zhou H, Li SL, Haque U, Tong SL, Glass GE, Bi P, Clements AC, Liu QY, Li CY, 2014. Spatiotemporal transmission dynamics of hemorrhagic fever with renal syndrome in china, 2005-2012. PLoS Neglect Trop D 8:e3344. 